\title{
SOME ASPECTS OF GERMINATION ANALYSIS
}

\author{
By A. V. LITHGOW, Officer-in-Charge,
}

Department of Agriculture's Seed-testing Station,

Palmerston North

Of the three factors which indicate quality in seed-purity, germination, and strain-germination is the one most fully appreciated by those trading in or sowing seed. Before germination can take place conditions must be suitable. The conditions can best be described as being suitable when there are present the required amounts_of water, warmth, and air, and, with certain seeds, light. In the laboratory suitable conditions for each species are provided and the resulting germination figures show the maximum germination possible under ideal conditions.

The problem facing the user of seed is how closely laboratory figures will indicate the results he will obtain under field conditions. There is ample evidence that seeds which have given high germination figures in the laboratory have failed to give satisfactory results in the paddocks.

In England it has been demonstrated that wheat dusted with certain mercuric dusts has given excellent results in the laboratory with both blotter and sand tests, but failed to continue growth after a favourable field strike.

In the U.S.A. early sowings of corn have often given disappointing results, even though the seed tested satisfactorily in the laboratory.

In New Zealand brassica and other species have not given the strike that results of germination anlysis would suggest could be expected. Although these cases are very much in a minority, they nevertheless cause concern and loss to the user and tend to destroy confidence in laboratory results. There is, however, still no substitute for the laboratory analysis and in most cases it provides an excellent indication of strike potential under reasonable field conditions.

In the reporting of germination results two figures are given: (1) the interim germination and (2) the final germination. 
The interim germination is the percentage of seeds that have produced normal seedlings in a comparatively short time and indicates the speed or velocity of germination.

There has been a growing tendency among users of seed to interpret the interim germination test as an indication of the vigour of the seed. It is suggested that it indicates only one aspect of vigour and that is the speed or velocity of germination. Undoubtedly speed of germination is a factor affecting strikes in the paddock. The very fact that a high percentage of seed can germinate rapidly tends to give seedlings a decided advantage in the field in the face of opposition from weed species.

Truly vigorous seed would be seed which not only possessed speed of germination, but could be expected to withstand rigorous conditions such as excessive cold, excessive wetness, or attacks by disease-producing organisms.

Efforts to produce a satisfactory vigour test have been made by seed testing stations for some years. In Holland a test was produced which regarded vigorous seedlings as those which were able to penetrate a certain depth of brick dust. In New Zealand a similar test using impacted sand was tried. In the United States of America a cold test was evolved. This subjected seeds to extremely cold conditions for a predetermined period and then placed them at their normal germinating temperature. There is no evidence to show that seeds which were satisfactory under the above tests possessed any particular vigour relating to conditions other than those under which they were tested. Seed, testing satisfactorily under the cold test, struck satisfactorily under those conditions in the soil, but not necessarily under other adverse conditions.

Causes of low interim germination are several. The first-a very significant cause-is age. One of the first signs of age in seed is the slowing down of the germination process; in other words, the interim count is lower.

Table I-Interim Counts on Seed Stored at Palmerston North.

\begin{tabular}{|c|c|c|c|c|c|c|}
\hline $\begin{array}{l}\text { Date of Test } \\
\text { Cowgrass }\end{array}$ & & $\begin{array}{c}9 / 53 \\
88\end{array}$ & $\begin{array}{c}9 / 54 \\
72\end{array}$ & $\begin{array}{c}9 / 55 \\
39\end{array}$ & $\begin{array}{c}9 / 56 \\
19\end{array}$ & $\begin{array}{c}3 / \mathrm{s}: \\
\quad 9\end{array}$ \\
\hline White clover ... & & 90 & 67 & 48 & 35 & 26 \\
\hline Crested dogstail & & 85 & 94 & 75 & 67 & 63 \\
\hline Italian ryegrass & & 79 & 72 & 71 & 61 & 70 \\
\hline Perennial ryegrass $90 \%$ & & 91 & 87 & 77 & 53 & 5.5 \\
\hline ryegrass $60 \%$ & $\ldots$ & 60 & 62 & 47 & 33 & 36 \\
\hline
\end{tabular}

Secondly, certain weedicides are particularly lethal and their effect on the germination of some seeds is rapid. 
Table 2-Interim Counts on Seed Stored in Open Containers with Hormone Weedicides.

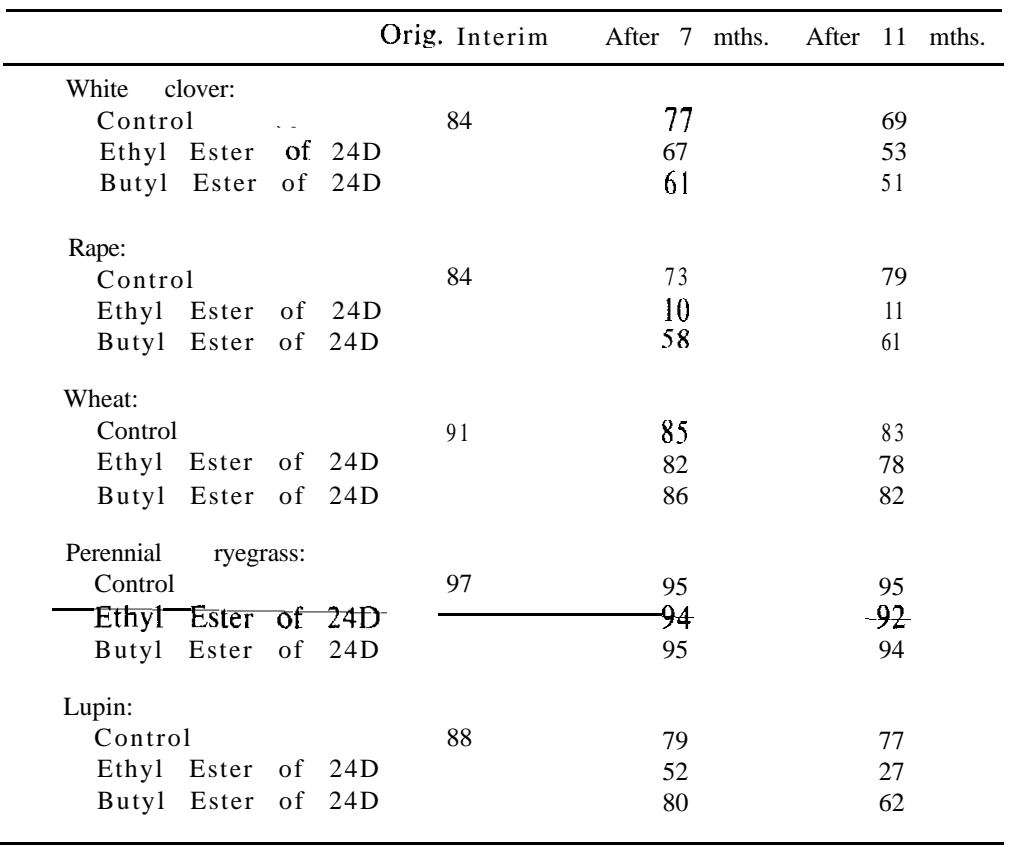

In both these cases the seed is dying and the low interim count is a true indication of the loss of the ability to germinate rapidly.

There are, however, other causes of low interim count. Freshly harvested seed often shows an unwillingness to germinate. Many samples of white clover seed taken from the paddock and rubbed by hand will give a nil interim count. At the time of count most of the seeds will be quite unchanged-hard seeds-and others will have taken up moisture-freshly swollen seeds-but will have refused to germinate. The same result is obtained from several other legumes. Machine dressed samples of lucerne and sweet blue lupin often include up to 50 per cent of hard seed. Hard seeds have not germinated because of the impermeability of their seeds coats to moisture. Their presence, therefore, depresses the interim count. There is some difference of opinion as to the true worth of hard seeds. It is accepted at present that the hard seeds of sweet blue lupin and lucerne germinate freely in the soil and therefore have the same value as normally germinating seed. Red clover hard seeds are credited with half the strike power and white clover hard seeds with one-third the strike power of normally germinating seed. 
Table 3-Results of Soil Tests of $\mathrm{H}$ ard Seed in Legumes-Summary of Results.

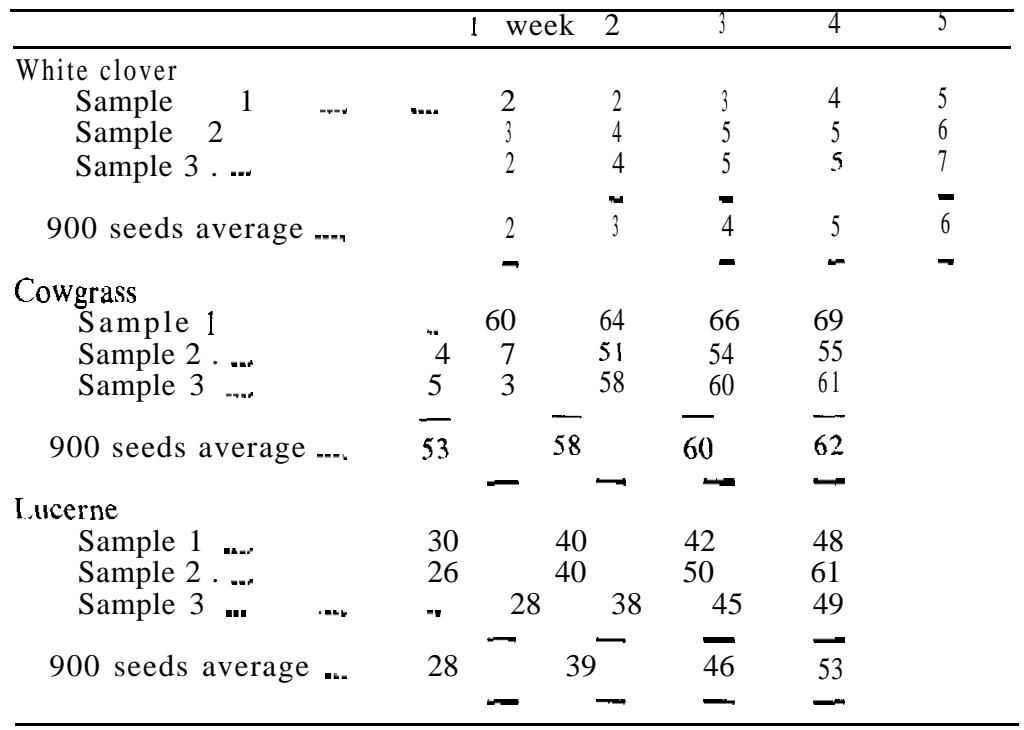

These tests were carried out in sterile soil under laboratory conditions and are not necessarily indicative of results that would be obtained under field conditions.

Freshly swollen seeds that have not germinated are not included in interim germination counts. If the seed coats of freshly swollen seeds of some species are punctured, they germinate normally. In most cases, however, this condition disappears if the seed to be germinated is submitted to lower temperature than the normal germinating temperature for the species. In practically all cases, if seed containing freshly swollen seeds is germinated after a period in store, the test shows fewer, if any, freshly swollen seeds.

A further type of dormancy is found in cereals, many of which require an after-harvesting ripening period. In the absence of this period a fuller and quicker germination may be obtained by pre-chilling the moist germination test before placing it to its normal germination temperature.

Samples of crested dogstail seed exhibit dormancy immediately after harvesting. This disappears quite rapidly except for a definite proportion of Individuals which are, however, prepared to germinate quite rapidly in the presence of strong light.

Freshly harvested short-rotation ryegrass seed almost invariably exhibits some degree of dormancy. This dormancy can be dispelled by pre-chilling the seed in a wet condition at $5^{\circ} \mathrm{C}$. for 4 days. 
In 1954,523 samples of shortrotation ryegrass seed submitted during February, March, and April were given two germination analyses.

1. Normal germination test.

2. Pre-chilled for 4 days at $5^{\circ} \mathrm{C}$. and then given normal germination test.

(See Tables 4 and 5.)

Fewer samples exhibit dormancy as the time from harvesting increases.

It appears therefore that the major causes of low interim are:-

1. Presence of dead or dying seed due to (a) old age; (b) the seed being killed by the presence of weedicides or some other unsatisfactory storage condition.

2. Presence of hard seed in legumes.

\section{Dormancy.}

The bare interim figure, if low, gives no indication which of these factors is the cause of lowness. Any of the above factors may be responsible. If the remainder of the seed is dead or dying, then the low interim is a warning that the seed is of poor strike value. If the low interim is due to dormancy, it is probable that this condition will have disappeared by the time the seed is sown. Under these circumstances good strikes may be obtained from lines of seed with low interim counts.

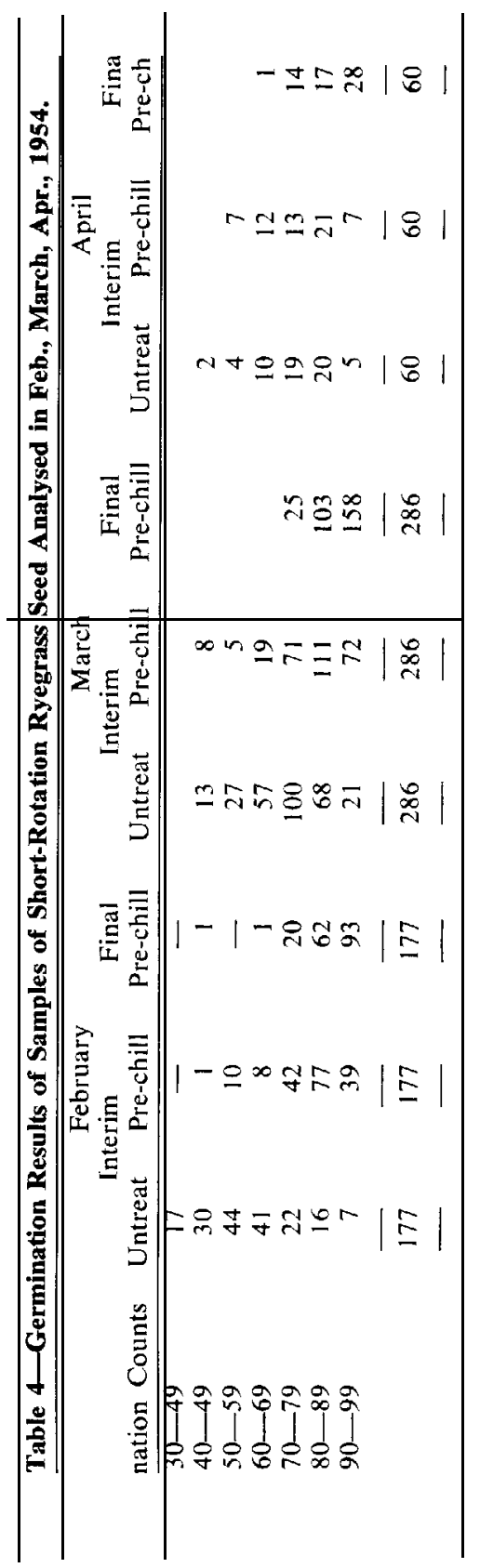


Table G-Comparison of Interim Counts on Pre-Chilled and

Non-Pre-Chilled Samples of Short-R otation Ryegrass

Submitted During Feb., M arch, and April.

\begin{tabular}{|c|c|c|c|c|c|c|}
\hline & & $\begin{array}{l}\text { Short-R } \\
\text { Percent }\end{array}$ & $\begin{array}{c}\text { tion } \\
\text { of } \\
\text { F e }\end{array}$ & $\begin{array}{l}\text { egrass } \\
\text { nples } \\
\text { u a r y }\end{array}$ & March & April \\
\hline \multirow[t]{2}{*}{ Interim } & untreated & below, 60 & & 51 & 14 & 10 \\
\hline & & over 60 &.-- & 49 & 86 & 90 \\
\hline \multirow[t]{2}{*}{ Interim } & prechill & below 60 & $\ldots$ & 6 & 4 & 10 \\
\hline & & over 60 & & 94 & 96 & 90 \\
\hline \multirow[t]{2}{*}{ Final } & pre-chill & below 60 & ...** & - & $=$ & - \\
\hline & & over 60 & …- & 100 & 100 & 100 \\
\hline
\end{tabular}

It is suggested that while a high interim count is undoubtedly a desirable characteristic, in the absence of further information a low interim should not necessarily condemn the seed.

\section{DISCUSSION}

Q. In the tests with weedicides was the final count down as well as the interim?

A. Yes. The danger of storing seeds and weedkiller near each other is not generally appreciated.

Q. Can the germination of paspalum be increased by leaving the seed in water at $90^{\circ} \mathrm{C}$. for half an hour'?

A. I do not know. In the laboratory, paspalum is tested very wet at $35^{\circ} \mathrm{C}$. in light.

Mr Allo: We have found that if you sow paspalum in the spring in rising temperatures and high soil moisture conditions you get a better take than in the autumn.

Q. In your longevity tests have you found a relationship to climate and moisture?

A. Yes, there seems to be a definite tie up with climatic conditions particularly humidity. 